\title{
Prediction of Design Margin for Diesel Exhaust Fluid Tank Bracket by FEA Approach
}

\author{
Sayali B. Pawar \\ M.Tech Final Year Student \\ Department of Mechanical Engineering \\ Walchand college of engineering, Sangli \\ Sangli, India
}

\author{
Dr. Ranjit G.Todkar \\ Professor \\ Department of Mechanical Engineering \\ Walchand college of engineering, Sangli \\ Sangli, India
}

\begin{abstract}
Diesel exhaust fluid is used to minimize the air pollution created by diesel engine. It is an aqueous urea solution made with $32.5 \%$ urea and $67.5 \%$ deionized water. It is used to lower nitrogen oxides concentration. Diesel exhaust fluid tank is supported on bracket.
\end{abstract}

The main objective of this project is to predict the robust FEA approach for diesel exhaust fluid tank bracket using Ansys Workbench tool. The current FEA analysis results are not close to test results. In this project, robust FEA modelling approach is developed which have frequency, acceleration and strain responses of simulation close to test results

Keywords: Diesel exhaust fluid tank bracket, Modal analysis, Power spectral density analysis.

\section{INTRODUCTION:}

In mechanical engineering, a bracket is intermediate component for fixing one part to another. Bracket is the intermediate between the two components and fixes the one to the other. It is used to support or hold the components together.

\section{ANALYSIS:}

Analysis of bracket is carried out in Ansys workbench tool. The assembly consist of fixture, bracket and tank. The fixture and bracket are made of aluminum and structural steel respectively. Diesel exhaust fluid tank is made of highdensity polyethylene rubber. Properties of materials are shown in table 1.

FEA model of bracket is shown in fig. (1). Fig (a) shows the FEA model of bracket in axial and lateral direction to obtain the frequency, acceleration and strain responses. Fig (b) shows the FEA model of bracket in vertical direction. The model is rotated because the gap between bracket and slip plate of shaker table in testing was less. To consider the actual testing condition, FEA model of bracket is rotated by $90^{\circ}$ in simulation. Modal analysis is required before performing random vibration analysis.
Table 1. Properties of materials

\begin{tabular}{|c|c|c|c|c|c|}
\hline$\underset{\dot{n}}{\dot{\theta}}$ & 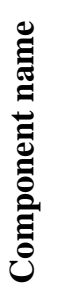 & 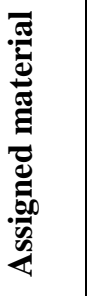 & 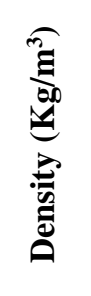 & 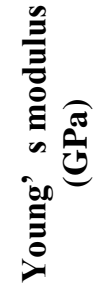 & 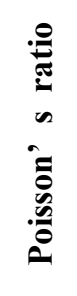 \\
\hline 1 & $\frac{\bar{v}}{\frac{v}{0}}$ & 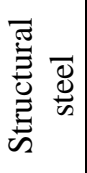 & 7800 & 210 & 0.3 \\
\hline 2 & 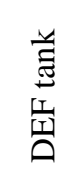 & 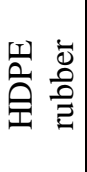 & 935 & 1 & 0.46 \\
\hline 3 & 冚 & 蔦 & 2770 & 71 & 0.33 \\
\hline
\end{tabular}

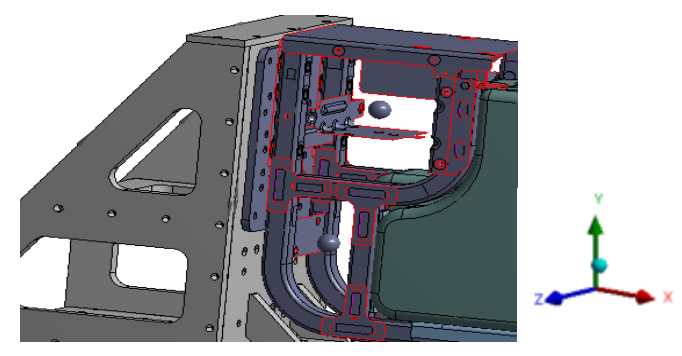

(a)

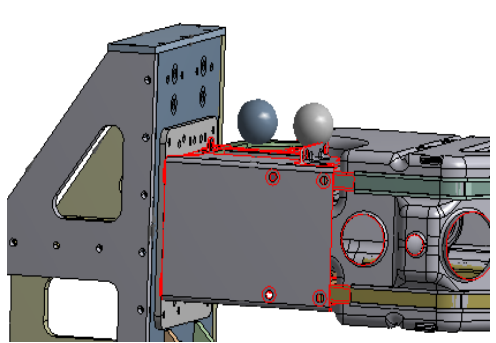

(b)

Fig 1. (a) FEA model of bracket for axial and lateral direction (b) FEA model of bracket for vertical direction 
Triangular element is used for meshing of fixture. Bracket and tank are meshed with quadrilateral element. The contact used between bracket and fixture for current model is bonded contact. Fixed support is given to the base plate of fixture.

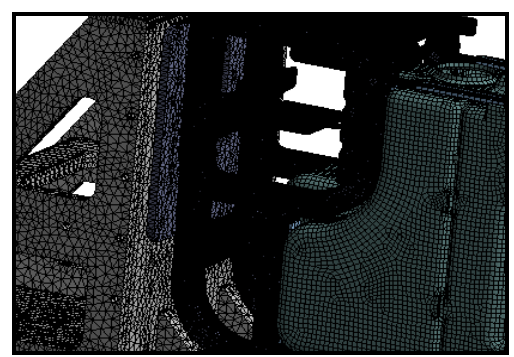

Fig 2. Mesh model

\section{Modal analysis and random vibration analysis:}

Modal analysis is used to determine the mode shapes and modal frequencies of bracket. Mode shape represents a specific pattern of vibration executed by a mechanical system at a specific frequency.

The governing equation for modal analysis is given as,

$$
M \ddot{x}(t)+K^{*} x(t)=0
$$

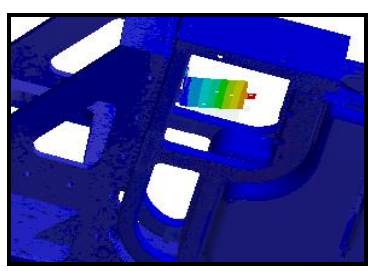

(a)

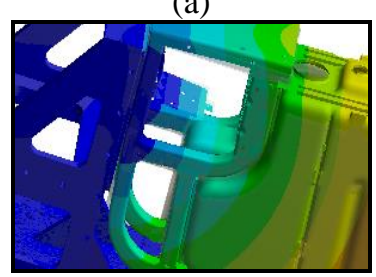

(b)

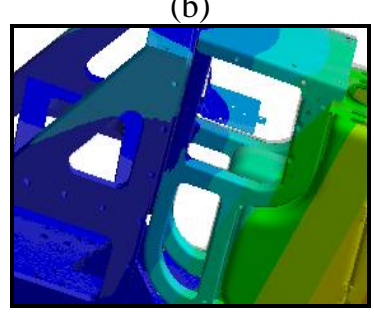

(c)

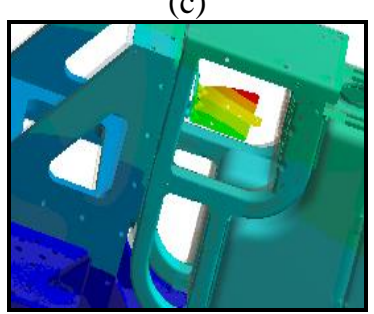

(d)

Fig 3. Mode shapes

Fig 3. (a) and fig 3. (d) show the same mode shape. Deformation of bracket is observed in vertical direction. Fig
3. (b) and (c) shows the same mode shape. Deformation of bracket is observed at the DEF tank.

For performing random vibration, power spectral density analysis is used to determine the frequency, acceleration and strain responses. The input PSD profile is applied to the base plate of fixture. The input frequency range is from 0-1000 $\mathrm{Hz}$.

\section{TESTING:}

Bracket is tested on shaker table for random vibration to obtain frequency, acceleration and strain responses. Bracket is fixed with fixture on slip late of shaker table. The test setup of bracket is shown in fig 4 .

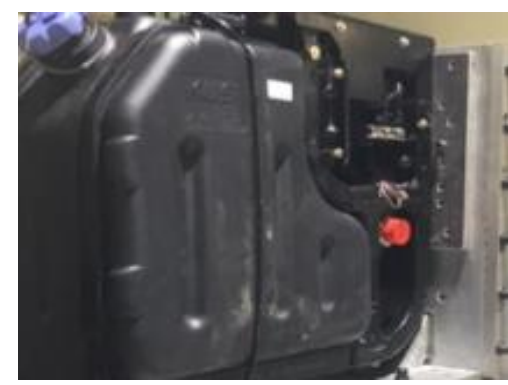

(a)

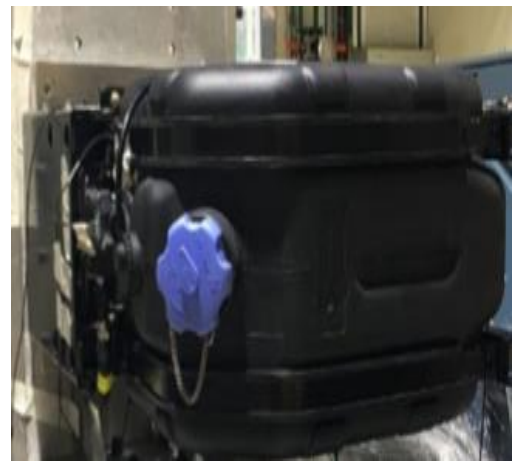

(b)

Fig 4. (a) Test setup of bracket for axial and lateral direction (b) Test setup of bracket for vertical direction

\section{COMPARISON OF TESTING TO SIMULATION RESULTS:}

The acceleration versus frequency graph for testing and simulation is plotted to find frequency at different peaks and compare it.

\section{(a) Axial (X) direction:}

The axial direction frequencies of bracket at different peaks is considered for comparison between testing and simulation results. The gap between testing and simulation for cceleration Grms and strain rms is determined in terms of percentage difference. 


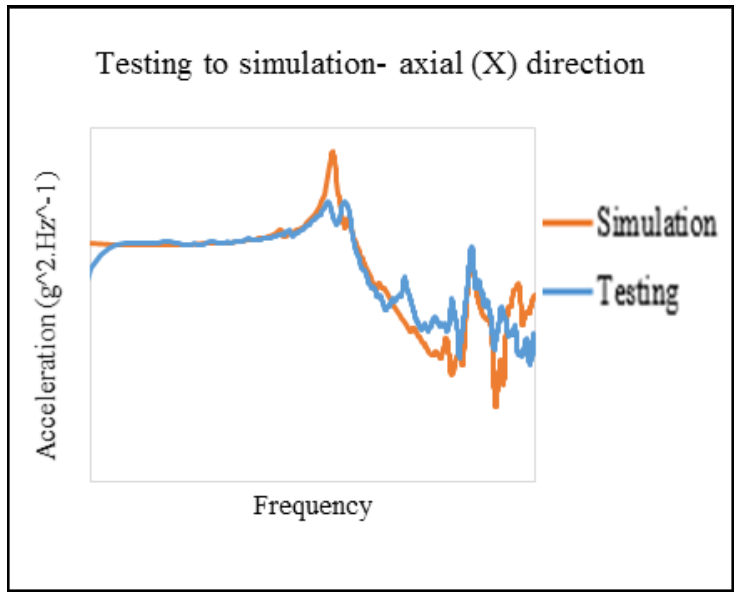

Fig 5. Acceleration versus frequency response in $\mathrm{X}$ direction

(i) Frequency response:

Table 2. Comparison of testing to simulation results

\begin{tabular}{|l|l|l|l|}
\hline Frequency & 1 peak & 2 peak & 3 peak \\
\hline $\begin{array}{l}\text { Percentage } \\
\text { difference }\end{array}$ & $4.76 \%$ & $4.02 \%$ & NA \\
\hline
\end{tabular}

(ii) Acceleration and strain response:

The percentage difference of acceleration Grms and strain rms are $41.80 \%$ and $4.64 \%$ respectively. The acceleration Grms of simulation is not close to test result.

\section{(b) Lateral (Z) direction:}

The lateral direction frequencies of bracket at different peaks is considered for comparison between testing and simulation results. The gap between testing and simulation for cceleration Grms and strain rms is determined in terms of percentage difference.

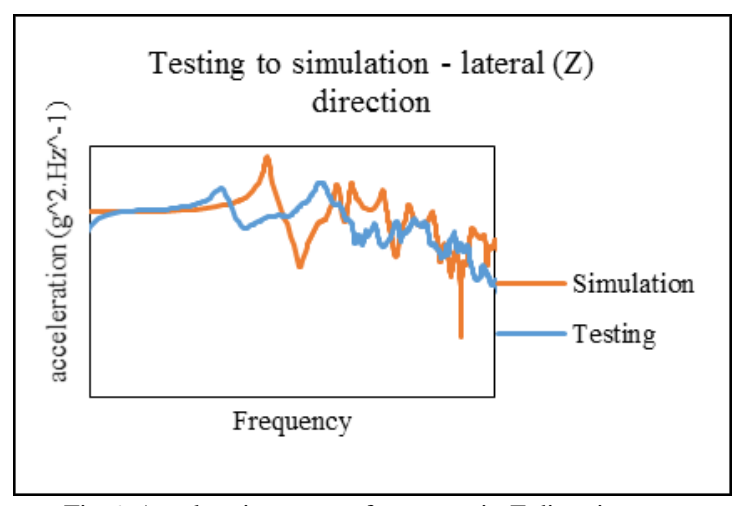

Fig 6. Acceleration versus frequency in $\mathrm{Z}$ direction

(i) Frequency response:

Table 3. Comparison of testing to simulation results

\begin{tabular}{|l|l|l|l|}
\hline Frequency & 1 peak & 2 peak & 3 peak \\
\hline $\begin{array}{l}\text { Percentage } \\
\text { difference }\end{array}$ & $39.48 \%$ & $17.67 \%$ & $7.34 \%$ \\
\hline
\end{tabular}

(ii) Acceleration and strain response:

The percentage difference of acceleration Grms and strain rms are $37.74 \%$ and $27.22 \%$ respectively. Acceleration Grms and strain rms values of simulation are not close to test results.

\section{(C) Vertical ( $Y$ ) direction:}

To find responses in vertical direction, bracket is rotated by $90^{\circ}$. Because in testing the gap between testing and slip plate of shaker table is minimum. To avoid damages to bracket, it is rotated.

The vertical direction frequencies of bracket at different peaks is considered for comparison between testing and simulation results. The gap between testing and simulation for acceleration Grms and strain rms is determined in terms of percentage difference.

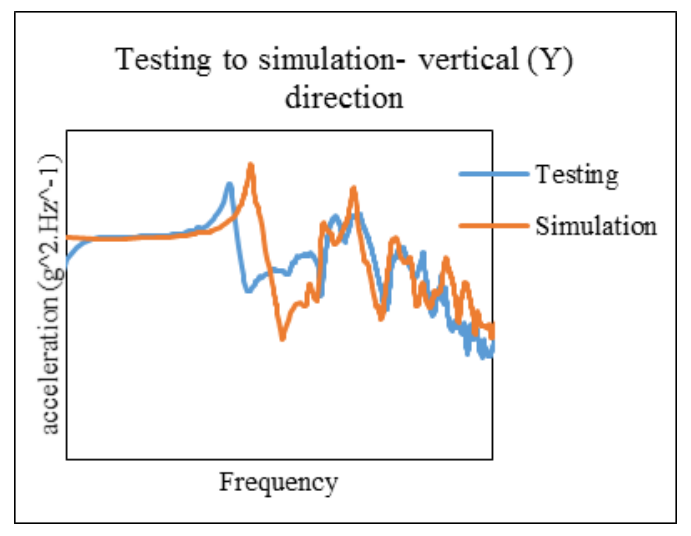

Fig 7. Acceleration versus frequency in $\mathrm{Y}$ direction

(i) Frequency response:

Table 4. Comparison of testing to simulation results

\begin{tabular}{|l|l|l|l|}
\hline Frequency & 1 peak & 2 peak & 3 peak \\
\hline $\begin{array}{l}\text { Percentage } \\
\text { difference }\end{array}$ & $20.11 \%$ & $0.79 \%$ & $12.47 \%$ \\
\hline
\end{tabular}

(ii) Acceleration and strain response:

The percentage difference of acceleration Grms and strain rms are $22.30 \%$ and $73.28 \%$ respectively.

The gap between testing and simulation results are not close to test results for $\mathrm{Z}$ and $\mathrm{Y}$ direction of bracket. The percentage gap of acceleration Grms is not close to test result in $\mathrm{X}$ direction of bracket. Hence different FEA modelling approaches are used in Ansys Workbench tool to get results close to test results.

\section{DIFFERENT FEA MODELLING APPROACHES:}

\section{Beam contact for bolted joint:}

In bonded contact load is directly transferred through flanges. In beam contact, load is transferred from one flange through beam to other flange. This type of contact is considered to replicate the actual load transfer through bolt joint. 


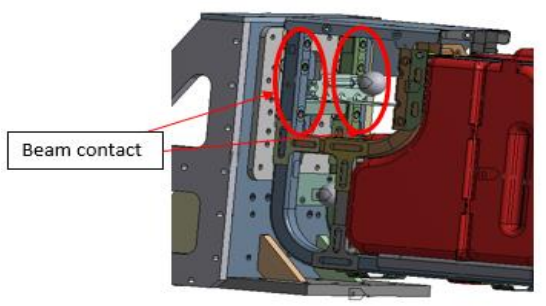

Fig 8. Location of Beam contact

Comparison of testing to simulation results

(a) Axial (X) direction:

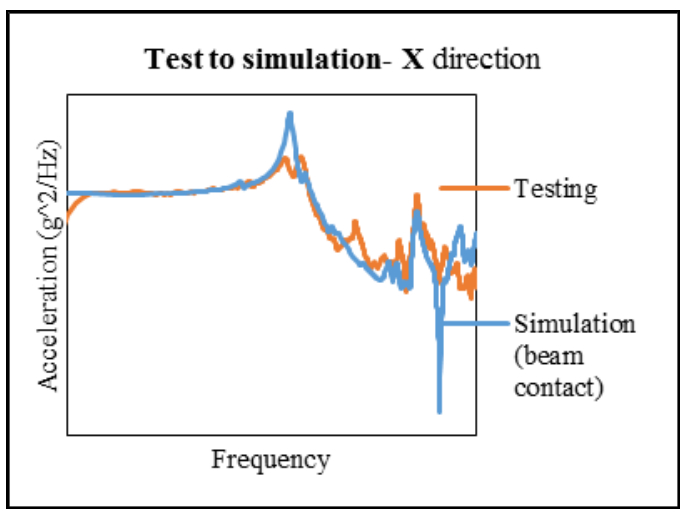

Fig 9. Acceleration versus frequency in $\mathrm{X}$ direction

(i) Frequency response:

Table 5. Comparison of testing to simulation results

\begin{tabular}{|l|l|l|l|}
\hline Frequency & 1 peak & 2 peak & 3 peak \\
\hline $\begin{array}{l}\text { Percentage } \\
\text { difference }\end{array}$ & $5.20 \%$ & $4.75 \%$ & NA \\
\hline
\end{tabular}

(ii) Acceleration and strain response:

The percentage difference of acceleration Grms and strain rms are $42.27 \%$ and $2.51 \%$ respectively.

\section{(b) Lateral (Z) direction:}

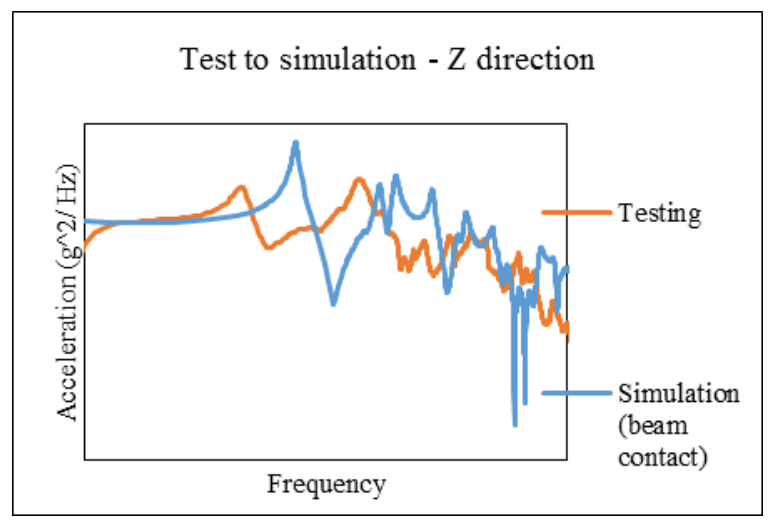

Fig 10. Acceleration versus frequency in $\mathrm{Z}$ direction (i) Frequency response:

Table 6. Comparison of testing to simulation results

\begin{tabular}{|l|l|l|l|}
\hline Frequency & 1 peak & 2 peak & 3 peak \\
\hline $\begin{array}{l}\text { Percentage } \\
\text { difference }\end{array}$ & $39.62 \%$ & $17.01 \%$ & $7.36 \%$ \\
\hline
\end{tabular}

(ii) Acceleration and strain response:

The percentage difference of acceleration Grms and strain rms are $37.25 \%$ and $27.05 \%$ respectively. The results are not within acceptance limit for beam contact between fixture and bracket.

(c) $\operatorname{Vertical}(Y)$ direction:

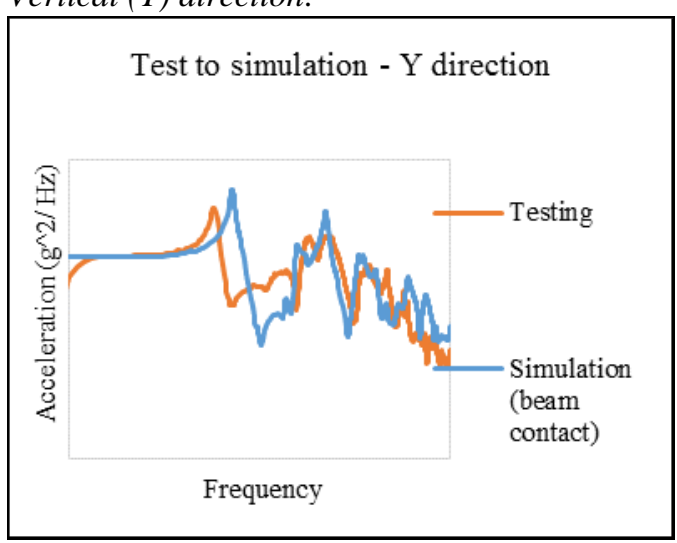

Fig 11. Acceleration versus frequency in $\mathrm{Y}$ direction

(i) Frequency response:

Table 7. Comparison of testing to simulation results

\begin{tabular}{|l|l|l|l|}
\hline Frequency & 1 peak & 2 peak & 3 peak \\
\hline $\begin{array}{l}\text { Percentage } \\
\text { difference }\end{array}$ & $19.23 \%$ & $0.64 \%$ & $13.30 \%$ \\
\hline
\end{tabular}

(ii) Acceleration and strain response:

The percentage difference of acceleration Grms and strain rms are $23.15 \%$ and $66.27 \%$ respectively.

\section{No separation contact:}

To restrict sliding motion and separation between parts in normal direction and allow sliding motion in tangential direction of fixture no separation contact is given between vertical and horizontal plate of fixture.

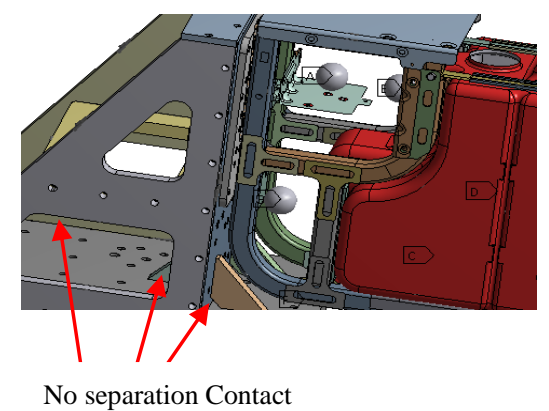

Fig. 12. Location of no separation contact 
Comparison of testing to simulation results:

(a) Axial direction:

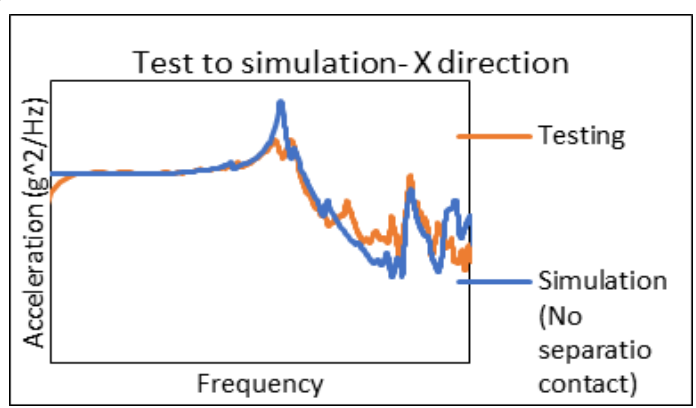

Fig 13. Acceleration versus frequency in $\mathrm{X}$ direction

(i) Frequency response:

Table 8. Comparison of testing to simulation results

\begin{tabular}{|l|l|l|l|}
\hline Frequency & 1 peak & 2 peak & 3 peak \\
\hline $\begin{array}{l}\text { Percentage } \\
\text { difference }\end{array}$ & $6.55 \%$ & $3.80 \%$ & $19.80 \%$ \\
\hline
\end{tabular}

(ii) Acceleration and strain response:

The percentage difference of acceleration Grms and strain rms are $40.58 \%$ and $54.37 \%$ respectively.

(b) Lateral (Z) direction:

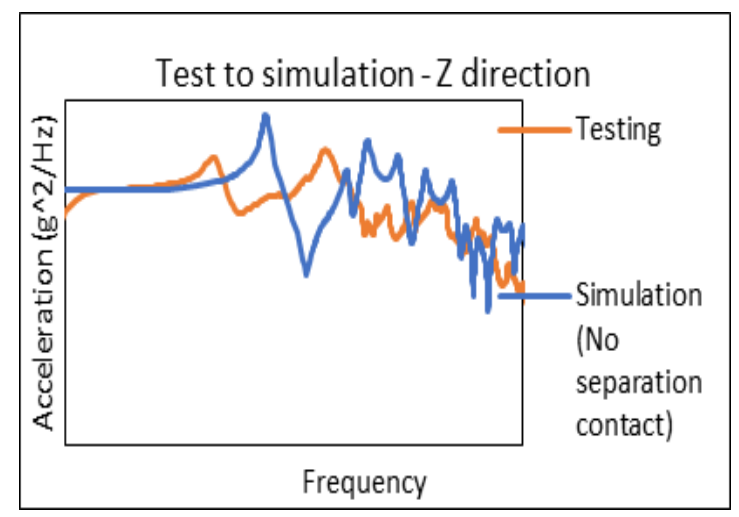

Fig 14. Acceleration versus frequency in $\mathrm{Z}$ direction

(i) Frequency response:

Table 9. Comparison of testing to simulation results

\begin{tabular}{|l|l|l|l|}
\hline Frequency & 1 peak & 2 peak & 3 peak \\
\hline $\begin{array}{l}\text { Percentage } \\
\text { difference }\end{array}$ & $40.02 \%$ & $16.12 \%$ & $8.89 \%$ \\
\hline
\end{tabular}

(ii) Acceleration and strain response:

The percentage difference of acceleration Grms and strain rms are $44.44 \%$ and $5.32 \%$ respectively. The acceleration Grms of simulation is not matching with testing result. (c) Vertical (Y) direction:

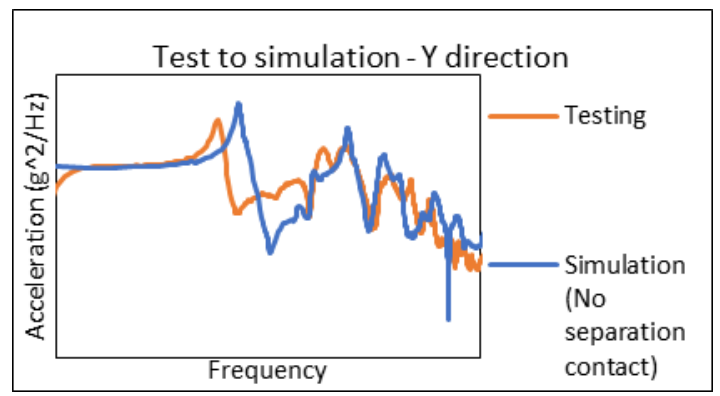

Fig 15. Acceleration versus frequency in $\mathrm{Y}$ direction

(i) Frequency response:

Table 10. Comparison of testing to simulation results

\begin{tabular}{|l|l|l|l|}
\hline Frequency & 1 peak & 2 peak & 3 peak \\
\hline $\begin{array}{l}\text { Percentage } \\
\text { difference }\end{array}$ & $19.51 \%$ & $0.71 \%$ & $10.56 \%$ \\
\hline
\end{tabular}

(ii) Acceleration and strain response:

The gap between testing and simulation results for acceleration Grms and strain rms are $21.92 \%$ and $78.10 \%$ respectively.

\section{Considering slip plate of shaker table:}

To consider the actual contacts between slip plate and fixture in testing condition, slip plate of shaker table is considered. The input is applied to slip plate instead of base plate of fixture. This can affect the input profile transmitted to bracket.

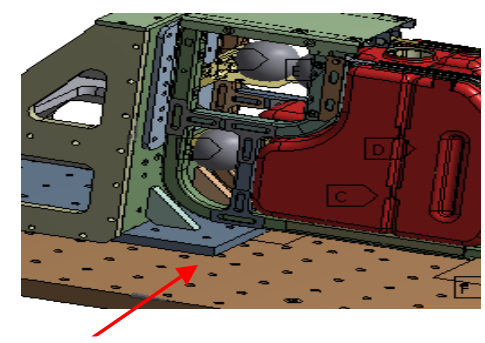

Slip pate

Fig. 16. Bracket with slip plate of shaker table

(a) Axial (X) direction:

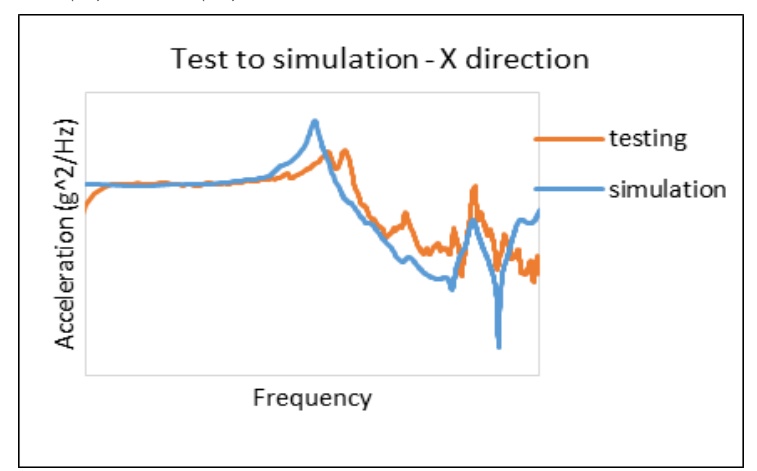

Fig 17. Acceleration versus frequency in $\mathrm{X}$ direction of bracket 
(i) Frequency response:

Table 11. Comparison of testing to simulation results

\begin{tabular}{|l|l|l|l|}
\hline Frequency & 1 peak & 2 peak & 3 peak \\
\hline $\begin{array}{l}\text { Percentage } \\
\text { difference }\end{array}$ & $13.16 \%$ & NA & $4.22 \%$ \\
\hline
\end{tabular}

(ii) Acceleration and strain response:

The gap between testing and simulation results for acceleration Grms and srain rms are $45.38 \%$ and $40.25 \%$ respectively.

(b) Lateral (Z) direction:

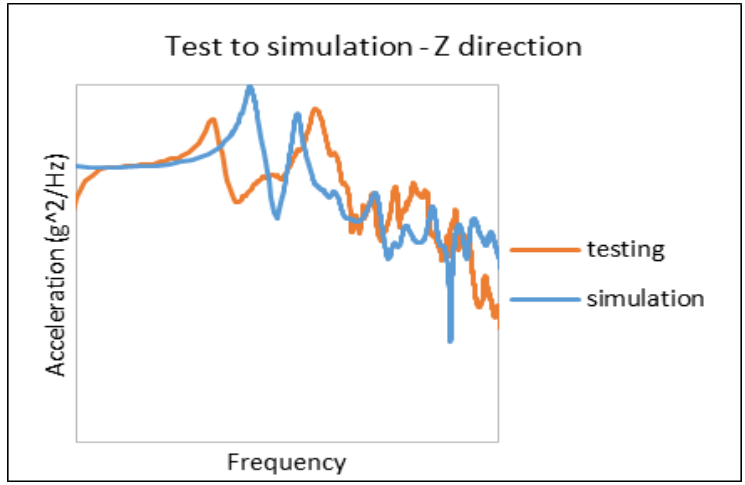

Fig 18. Acceleration versus frequency in $\mathrm{Z}$ direction of bracket

(i) Frequency response:

Table 12. Comparison of testing to simulation results

\begin{tabular}{|l|l|l|l|}
\hline Frequency & 1 peak & 2 peak & 3 peak \\
\hline $\begin{array}{l}\text { Percentage } \\
\text { difference }\end{array}$ & $32.32 \%$ & $19.00 \%$ & $2.06 \%$ \\
\hline
\end{tabular}

(ii) Acceleration and strain response:

The gap between testing and simulation results for acceleration Grms and srain rms are $32.48 \%$ and $68.30 \%$ respectively.

(c) Vertical (Y) direction:

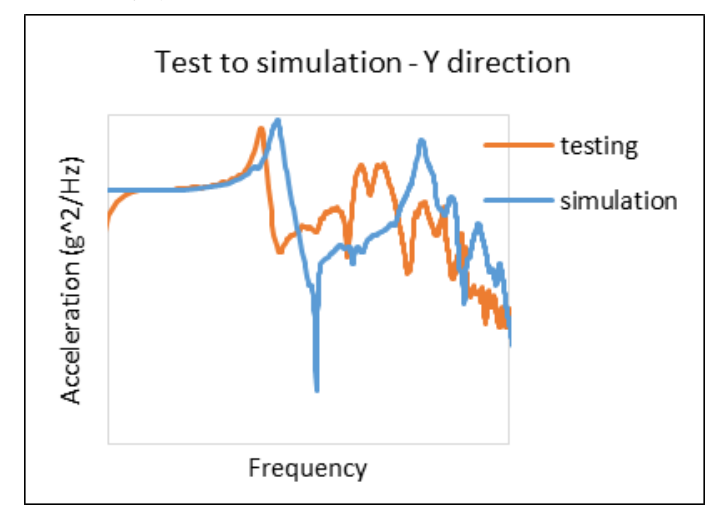

Fig 19. Acceleration versus frequency in $\mathrm{Y}$ direction of bracket

(i) Frequency response:

Table 13. Comparison of testing to simulation results

\begin{tabular}{|l|l|l|l|}
\hline Frequency & 1 peak & 2 peak & 3 peak \\
\hline $\begin{array}{l}\text { Percentage } \\
\text { difference }\end{array}$ & $18.82 \%$ & $2.70 \%$ & NA \\
\hline
\end{tabular}

(ii) Acceleration and strain response:

The gap between testing and simulation results for acceleration Grms and strain rms are $30.17 \%$ and $24.96 \%$ respectively.

\section{With slip plate considering material damping:}

Material damping factor of structural steel, EPDM rubber and magnesium is considered. Damping factor considered for structural steel, EPDM rubber and magnesium material are $2 \%, 5 \%$ and $1 \%$ respectively. There is no change in frequency response but the amplitude of acceleration and strain is reduced.

\section{Acceleration and strain response:}

The gap between testing and simulation results for acceleration Grms and strain rms are given in table.

Table 14. Comparison of testing to simulation results

\begin{tabular}{|l|l|l|l|}
\hline $\begin{array}{c}\text { Percentage } \\
\text { difference }\end{array}$ & $\begin{array}{l}\text { X } \\
\text { direction }\end{array}$ & Y direction & Z direction \\
\hline $\begin{array}{l}\text { Acceleration } \\
\text { Grms }\end{array}$ & $28.43 \%$ & $0.68 \%$ & $4.76 \%$ \\
\hline Strain rms & $0.94 \%$ & $3.82 \%$ & $7.06 \%$ \\
\hline
\end{tabular}

\section{SUMMARY/ CONCLUSION:}

This paper presents the modal and random vibration analysis of bracket. Different FEA modelling approaches are used to determine the robust approach that gives results close to test results. From different modelling approaches, bracket with slip plate of shaker table considering material damping shows frequency, acceleration Grms and strain rms response close to test results as compared to other FEA modelling approaches. Hence recommended robust FEA analysis approach is considering slip plate of shaker table with material damping.

\section{ACKNOWLEDGEMENT:}

The author wish to thank Amar A. Mali, Kishor Deshmukh and Giridharan Balakumar Applied Mechanics Engineer, CES, Cummins Technical Center India, Pune for providing the technical support for this work.

Note: The values of frequency, acceleration $\left(\mathrm{g}^{2} / \mathrm{Hz}\right)$, acceleration Grms and strain rms are not displayed as the data is confindential of Cummins India ltd.

\section{REFERENCES:}

[1] Sreekanth Dondapati, Mudit Trivedi, Raja Sekhar Dondapatia, Divya Chandra, "Investigation on the mechanical stresses in a muffler mounting bracket using Root Cause Failure Analysis (RCFA), finite element analysis and experimental validation." Engineering Failure Analysis 81 (2017) 145- 154.

[2] Yu- Gyeong Kim, Yung- Jing Jung, Hyun- Soo Kim, Hee- Jae Ahn, "Design assessment of triangular support bracket for manufacturability." Fusion engineering design (2015).

[3] Sang Eui Lee, Anil Kumar Thayamballi, Jeom Kee Paik, "Ultimate strength of steel brackets in ship structures." Ocean Engineering 101 (2015) 182- 200.

[4] Jingshu Wu, Ray Ruichong Zhang, Steve Radons, Xiaole Long, Karl K. Stevens, "Vibration analysis of medical devices with a calibrated FEA model." Computers and Structures 80 (2002) 1081-1086.

[5] Jan Posta, Martin Hataj, Bobert Jara, Petr Ptacek, Petr Kuklik, "Comparison of the use of angle brackets in timber joints with Eurocode 5." Construction and building materials 205 (2019) 611-621 
[6] Hongfeng Ma, Jixin Wang, Genwen Li, Jianfei Qiu, "Fatigue redesign of failed sub frame using stress measuring, FEA and British Standard 7608." Engineering Failure Analysis 97 (2019) 103-114.

[7] Yen-Chen Chiang, Sukru Guzey, "Dynamic analysis of above ground open-top steel tanks subjected to wind loading."Engineering structures 198 (2019) 109496.

[8] Seungiae Lee, Jaeseong Park, Sudeok Shon, Changhoon Kang, "Seismic performance evaluation of the ceiling bracket type modular joint with various bracket parameters." Journal of constructional steel research 150 (2018) 298-325. 